\title{
Case-control study on factors associated with crown fractures in the primary dentition
}

\section{Patrícia CORRÊA-FARIA ${ }^{(a)}$ Suzane PAIXÃO-GONÇALVES(a) Saul Martins PAIVA(a) Maria Letícia RAMOS-JORGE(b) Isabela Almeida PORDEUS(a)}

(a) Universidade Federal de Minas Gerais - UFMG, School of Dentistry, Department of Pediatric Dentistry and Orthodontics, Belo Horizonte, MG, Brazil.

(b) Universidade Federal dos Vales do Jequitinhonha e Mucuri - UFVJM, School of Dentistry, Department of Pediatric Dentistry, Diamantina, MG, Brazil.

Declaration of Interests: The authors certify that they have no commercial or associative interest that represents a conflict of interest in connection with the manuscript

Corresponding Author:

Patrícia Corrêa-Faria

Email: patriciafaria.faria09@gmail.com

DOI: 10.1590/1807-3107BOR-2015.vol29.0079

Submitted: Jun 27, 2014

Accepted for publication: Feb 20, 2015

Last revision: May 18, 2015

\begin{abstract}
The purpose of the present study was to identify the factors associated with dental trauma in preschool children. This case-control study was nested in a population-based cross-sectional study involving a random sample of 301 children one to five years of age in the city of Diamantina, Brazil. The case group was made up of children with at least one fractured deciduous tooth, and the control group was made up of children with no deciduous tooth fracture. The two groups were matched for age in a proportion of one control for every case. The dependent variable was "dental trauma," diagnosed according to the criteria proposed by Andreasen and Andreasen. The independent variables were overjet, measured and considered accentuated when surpassing $3 \mathrm{~mm}$, and lip coverage, classified as adequate or inadequate. Clinical oral examinations were performed by calibrated dentists. The parents provided information on the socioeconomic indicators. Statistical analysis involved the McNemar test and logistic regression. Each group (case and control) was composed of 92 children. In the bivariate analysis, traumatic dental injury (TDI) was associated with overjet $>3 \mathrm{~mm}(\mathrm{p}=0.001)$, inadequate lip coverage $(\mathrm{p}<0.001)$, mother's schooling $(p=0.028)$ and household income $(p<0.001)$. In the multivariate analysis, only inadequate lip coverage was associated with TDI (OR: 5.35; 95\% CI: 1.37-20.85). In conclusion, the case group children had a 5.3 - fold more likely chance of presenting inadequate lip coverage, compared with the control children.
\end{abstract}

Keywords: Tooth Injuries; Case-Control Studies; Tooth, Deciduous.

\section{Introduction}

Traumatic dental injury (TDI) is a common occurrence in the primary dentition. Epidemiological studies carried out in different countries reveal a variety of prevalence rates, such as $6.2 \%$ among Indian children ${ }^{1}$ and $25.6 \%$ among Irish children. ${ }^{2}$ In Brazil, the prevalence rates of TDI in the primary dentition are reported to range from $9.4 \%^{3}$ to $62.0 \%$. These high frequencies of occurrence and the impact on both the child and family make TDI a public health concern. ${ }^{5,6}$ Moreover, children with TDI in the primary dentition may complain of pain, emotional discomfort stemming from altered facial esthetics and problems concerning development of the occlusion and permanent teeth. ${ }^{78}$ 
The etiology of TDI in the primary dentition is related to biological, socioeconomic and environmental factors. $4,9,10,11,12,13,14,15,16$ Accentuated overjet, inadequate lip coverage, gender, age $\mathrm{e}^{4,15,17}$ and socioeconomic indicators (household income and parents' schooling) are reported to be associated with a greater TDI prevalence rate in the primary dentition. ${ }^{15,18,19}$ Knowledge about factors associated with TDI has been acquired from cross-sectional studies and has provided important information for the drafting of preventive measures and for oral healthcare planning. ${ }^{11,20}$ However, the cross-sectional study design does not allow the evaluation of multiple risk exposures or the simultaneous identification of different risk factors. Thus, different designs (e.g., case-control studies, prospective studies, etc.) are needed to allow the simultaneous investigation of a set of potential risk factors ${ }^{21}$ that may be associated with TDI in the primary dentition, as well as possible interrelations among these factors.

The purpose of this study was to identify risk factors for TDI in the primary dentition.

\section{Methodology}

\section{Study design and sample characteristics}

A population-based case-control study was carried out among children one to five years of age treated during immunization campaigns in 2010 and 2011. This case-control study was nested in a cross-sectional study ${ }^{22}$ with a sample of 381 children one to five years of age from Diamantina, Brazil. Cases and controls were selected during the cross-sectional study. The case group was composed of children with at least one fractured deciduous tooth, as determined by the clinical exam. The control group was composed of children with a non-fractured deciduous tooth. The two groups were matched for age at a proportion of one control for every case. Children with missing incisors due to exfoliation, and those with major decay from dental caries in the upper or lower incisors, were excluded.

In this study, TDI was considered a dependent variable. The following risk factors were investigated: gender, overjet, lip coverage, mother's schooling, father's schooling and household income.
The sample size was calculated to detect an odds ratio (OR) of 2.0 between cases and controls, in order to have an $80 \%$ power of demonstrating a significant difference between groups at the 5\% level. The calculation was performed by using the proportion of children with accentuated overjet who exhibited TDI (58.9\%) in a previous cross-sectional study. ${ }^{22}$ The LEE (Laboratório de Epidemiologia e Estatística) software program was used to calculate the sample size, set at 103 children for each group.

Systematic sampling was adopted. Children were organized in a line according to their order of arrival for vaccination. After vaccination, the children were submitted to an oral exam in the same order. Systematic selection was used, where the first child is examined, the second is not, the third is examined, and so on.

\section{Calibration exercise}

Calibration was performed using images of different clinical cases in two separate sessions, with a one-week interval between sessions. Kappa coefficients were calculated. Minimum intraexaminer and interexaminer agreement was 0.81 and 0.80 , respectively.

\section{Clinical data collection}

The upper and lower incisor overjet and lip coverage were evaluated by a clinical oral examination. The children sat in a chair facing the examiner and a window, to maximize the use of natural light. The examiner used sterilized mouth mirrors (Duflex SS White, Rio de Janeiro, Brazil), a millimeter periodontal probe (Duflex SS White, Rio de Janeiro, Brazil), tongue depressors and gauze, in compliance with biosafety standards. Younger children were examined in the knee-to-knee position. Dental trauma was the dependent variable, diagnosed according to the criteria proposed by Andreasen and Andreasen. ${ }^{5}$ Since radiographs are not viable in epidemiological surveys ${ }^{23}$ root and alveolar fractures were not recorded in the present study.

Overjet was measured using a millimeter periodontal probe (Duflex SS White, Rio de Janeiro, Brazil) positioned parallel to the occlusal plane, and was considered accentuated when surpassing $3 \mathrm{~mm}$. Lip coverage was evaluated without the 
child's knowledge that he/she was being observed. Adequate lip coverage was recorded when the upper lip completely covered the maxillary incisors at rest. Inadequate lip coverage was recorded when part of the dental crown remained visible. ${ }^{24,25}$

\section{Non-clinical data collection}

Information on socioeconomic aspects (monthly household income, parent's schooling, child's age and gender) was gathered through interviews with parents/guardians. The interview was conducted using a form previously formulated for this study. Income was categorized based on the Brazilian minimum monthly wage. ${ }^{20}$ Parent's schooling (years of study) was categorized based on a cutoff point of eight years, which corresponds to the duration of a primary school education in Brazil. ${ }^{20}$

\section{Statistical analysis}

Data analysis was performed using the Statistical Package for the Social Sciences (SPSS for Windows, version 19.0, SPSS Inc. Chicago, USA), and included frequency distribution and association tests. Associations between TDI and the independent variables were determined using the McNemar test. This test was indicated owing to the pairing of the sample. Multivariate analysis was performed using logistic regression. The variables selected to construct the adjusted model had a $\mathrm{p}$ value of $<0.05$ in the bivariate analysis. The odds ratios (OR) and their respective confidence intervals were estimated at $95 \%$.

This study received the approval of the Human Research Ethics Committee of the Universidade Federal de Minas Gerais - UFMG, Brazil (registered under \#232.444). The participants' rights were protected and parents/guardians signed a statement of informed consent prior to their participation. Children with dental problems were referred to the pediatric dental clinical of the university for free treatment.

\section{Results}

A total of 184 children participated in the study: 92 with TDI and 92 without TDI. The mean age was 44.38 months (standard deviation: 12.86 months). The maxillary left central incisor was the most affected tooth $(21.5 \%)$.
Table 1 shows the associations between TDI in the primary dentition and the socioeconomic variables. The higher frequency of inadequate lip coverage $(p<0.001)$ and accentuated overjet $(p<0.001)$ was observed among children in the case group. TDI was significantly associated with socioeconomic indicators of the mothers' schooling $(p=0.028)$ and household income $(p<0.001)$.

In the adjusted multivariate logistic regression (Table 2), inadequate lip coverage was the only variable that remained significantly associated with TDI (OR: 5.35; 95\% CI: 1.37-20.85), independently of the overjet. Thus, the case group children (TDI) had a 5.3-fold greater chance of presenting inadequate lip coverage, compared with the control children.

\section{Discussion}

The present investigation examined associations between the occurrence of TDI in deciduous teeth and gender, overjet, lip coverage and socioeconomic indicators, based on a case-control design. The participants were selected from a population-based cross-sectional study carried out in the city of Diamantina, Brazil, involving preschool children, and were allocated to two groups - one with TDI and the other without TDI.

No significant difference was found between the groups in regard to gender, corroborating the findings reported in previous studies. ${ }^{1,26}$ This lends support to the hypothesis that boys and girls between one and five years of age are exposed to the same risk factors for TDI, ${ }^{12}$ since they develop the same activities and play the same games. However, there is no consensus in the literature regarding this association. Comparatively, a number of cross-sectional studies have reported that boys are more prone to TDI in comparison with girls of the same age., 2,11,27

In the bivariate analysis, TDI was more prevalent among children with an overjet greater than $3 \mathrm{~mm}$, corroborating findings reported in cross-sectional studies. ${ }^{2,11,14,28}$ This association may be explained by the greater inclination of the anterior teeth, which makes the maxillary incisors more exposed to impact, and, consequently, to TDI. However, one must exert caution toward how accentuated overjet is classified when comparing studies that assess this association, since the cutoff point for this variable ranges from 3 to $5 \mathrm{~mm} \cdot{ }^{20,27}$ 
Table 1. Associations between gender, overjet, lip coverage, socioeconomic indicators and TDI among preschool children in Diamantina, Brazil

\begin{tabular}{|c|c|c|c|}
\hline & Cases (n = 92) & Controls ( $n=92)$ & $p$-value \\
\hline \multicolumn{4}{|l|}{ Variables related to the child } \\
\hline Gender & & & 0.456 \\
\hline Male & $52(52.0 \%)$ & $48(48.0 \%)$ & \\
\hline Female & $40(47.6 \%)$ & $44(52.4 \%)$ & \\
\hline Overjet (mm) & & & $<0.001$ \\
\hline$\leq 3$ & $64(43.8 \%)$ & $82(56.2 \%)$ & \\
\hline$>3$ & $28(73.7 \%)$ & $10(26.3 \%)$ & \\
\hline Lip coverage & & & $<0.001$ \\
\hline Adequate & $72(44.7 \%)$ & 89 (55.3\%) & \\
\hline Inadequate & $20(87.0 \%)$ & $3(13.0 \%)$ & \\
\hline \multicolumn{4}{|l|}{ Socioeconomic indicators } \\
\hline Mother's schooling & & & 0.028 \\
\hline$>8$ years & $59(53.2 \%)$ & $52(46.8 \%)$ & \\
\hline$\leq 8$ years & 31 (44.3\%) & 39 (55.7\%) & \\
\hline Father's schooling & & & 0.248 \\
\hline$>8$ years & $41(56.2 \%)$ & $32(43.8 \%)$ & \\
\hline$\leq 8$ years & $43(45.3 \%)$ & $52(54.7 \%)$ & \\
\hline \multicolumn{4}{|l|}{ Household income } \\
\hline$\geq 2$ times the minimum wage & $21(58.3 \%)$ & $15(41.7 \%)$ & $<0.001$ \\
\hline$<2$ times the minimum wage & 69 (47.9\%) & 75 (52.1\%) & \\
\hline
\end{tabular}

Inadequate lip coverage is also considered a factor associated with TDI in the primary dentition. The lips play an important role in protecting the maxillary incisors, by absorbing part of the impact during a traumatic event. Thus, inadequate lip seal can increase the chance of TDI. In the present study, we found that children in the case group were more likely to be exposed to the risk factor of inadequate lip coverage. This is in agreement with findings reported in previous investigations, albeit conducted with different study designs. ${ }^{11,20}$ In contrast, a retrospective study involving children treated at a private clinic found no association between TDI and lip coverage. ${ }^{13}$ Although the study cited also had a case-control design, the comparison with the present findings should be made with caution, due to differences in the sample selection process, since the present investigation was a population-based study. The association between TDI and overjet lost its statistical significance in the logistic regression analysis. This result suggests that overjet acted as a confounding factor in the association between inadequate lip coverage and TDI in the primary dentition.
Socioeconomic indicators (household income and parents' schooling) were associated with TDI in the primary dentition in the bivariate analysis. However, in the multivariate analysis, socioeconomic characteristics were not associated with TDI. ${ }^{11,20,27}$ Studies addressing socioeconomic indicators report conflicting results, since some investigations found that families with greater purchasing power have more access to swimming pools, bicycles, roller skates and other activities that predispose children to falls and collisions that can result in TDI. ${ }^{29}$ Moreover, this association may further be explained by the non-observance of safety rules. ${ }^{18}$ In contrast, one study found that the prevalence of TDI was greater among children from socially vulnerable families and those whose mothers had a lower schooling level. ${ }^{17}$ Thus, the association between TDI and socioeconomic characteristics is inconsistent, and the differences encountered may be explained by the methods employed to evaluate these factors.

Study limitations include the absence of a radiographic examination. Some cases of TDI may 
Table 2. Adjusted logistic regression model for independent variables in children with TDI; Diamantina, Brazil

\begin{tabular}{|c|c|c|}
\hline & $\begin{array}{c}\text { Adjusted OR } \\
(95 \% \mathrm{Cl})\end{array}$ & $p$-value \\
\hline \multicolumn{3}{|l|}{ Model 1} \\
\hline Overjet (mm) & & 0.104 \\
\hline$\leq 3$ & 1 & \\
\hline$>3$ & $2.20(0.84-5.74)$ & \\
\hline Lip coverage & & 0.024 \\
\hline Adequate & 1 & \\
\hline Inadequate & $4.93(1.23-19.76)$ & \\
\hline Mother's schooling & & 0.921 \\
\hline$>8$ years & 1 & \\
\hline$\leq 8$ years & $0.96(0.49-1.87)$ & \\
\hline Household income & & 0.316 \\
\hline$\geq 2$ times the minimum wage & 1 & \\
\hline$<2$ times the minimum wage & $0.66(0.29-1.48)$ & \\
\hline \multicolumn{3}{|l|}{ Model 2} \\
\hline Overjet (mm) & & 0.068 \\
\hline$\leq 3$ & 1 & \\
\hline$>3$ & $2.39(0.93-6.09)$ & \\
\hline Lip coverage & & 0.029 \\
\hline Adequate & 1 & \\
\hline Inadequate & $4.66(1.17-18.53)$ & \\
\hline Household income & & 0.302 \\
\hline$\geq 2$ times the minimum wage & 1 & \\
\hline$<2$ times the minimum wage & $0.66(0.30-1.44)$ & \\
\hline \multicolumn{3}{|l|}{ Model 3} \\
\hline Overiet (mm) & & 0.124 \\
\hline$\leq 3$ & 1 & \\
\hline$>3$ & $2.02(0.84-4.96)$ & \\
\hline Lip coverage & & 0.015 \\
\hline Adequate & 1 & \\
\hline Inadequate & $5.35(1.37-20.85)$ & \\
\hline
\end{tabular}

have been missed because diagnosis required more than just a clinical examination. Another limitation was the fact that the calibration was conducted only by the observation of images. Calibration by the clinical examination of the children would have allowed a more detailed observation of the types of TDI. However, this study has strong points that should be pointed out, such as the investigation of a set of potential exposures to risk that may be associated with the etiology of TDI. Moreover, the acquisition of data from a population-based sample, in combination with the case-control design, underpins the results with stronger evidence, in comparison with previous investigations using a cross-sectional design or employing a hospital-based sample.

\section{Conclusion}

In conclusion, the present findings confirm that inadequate lip coverage was associated with TDI in the primary dentition. This underscores the importance of preventive measures. Preventing TDI can be accomplished by parent/guardian supervision of the child, and other measures, which include avoiding the use of walkers, and using mouthguards during sports or game playing where interpersonal contact is made. Actions such as these should be avoided because they predispose the child to TDI, by causing alterations in occlusion and oral musculature. Another way to avoid predisposition to TDI is to eliminate harmful oral habits, such as the prolonged use of pacifiers and bottles.

\section{Acknowledgments}

This study had the support of the following Brazilian agencies: National Research Commission, Ministry of Science and Technology (Conselho Nacional de Desenvolvimento Científico e Tecnológico - CNPq; Ministério da Ciência, Tecnologia e Inovação - MCT) and the State of Minas Gerais Research Foundation (Fundação de Amparo à Pesquisa do Estado de Minas Gerais - FAPEMIG). 


\section{References}

1. Shekhar MG, Mohan R. Traumatic dental injuries to primary incisors and the terminal or occlusal plane relationship in Indian preschool children. Community Dent Health. 2011 Mar;28(1):104-6.

2. Norton E, O'Connell AC. Traumatic dental injuries and their association with malocclusion in the primary dentition of Irish children. Dent Traumatol. 2012 Feb;28(1):81-6.

3. Oliveira LB, Marcenes W, Ardenghi TM, Sheiham A, Bönecker M. Traumatic dental injuries and associated factors among Brazilian preschool children. Dent Traumatol. 2007 Apr;23(2):76-81.

4. Viegas CM, Scarpelli AC, Carvalho AC, Ferreira FM, Pordeus IA, Paiva SM. Predisposing factors for traumatic dental injuries in Brazilian preschool children. Eur J Paediatr Dent. 2010 Jun;11(2):59-65.

5. Andreasen JO, Andreasen FM. Dental trauma: quo vadis. Tandlaegebladet. 1989 Aug;93(11):381-4.

6. Kramer PF, Feldens CA, Ferreira SH, Bervian J, Rodrigues $\mathrm{PH}$, Peres MA. Exploring the impact of oral diseases and disorders on quality of life of preschool children. Community Dent Oral Epidemiol. 2013 Aug;41(4):327-35.

7. Diab M, elBadrawy HE. Intrusion injuries of primary incisors. Part I: review and management. Quintessence Int. 2000 May;31(5):327-34

8. Aldrigui JM, Abanto J, Carvalho TS, Mendes FM, Wanderley MT, Bönecker M,et al. Impact of traumatic dental injuries and malocclusions on quality of life of young children. Health Qual Life Outcomes. 2011 Sep 24;9:78.

9. Granville-Garcia AF, Menezes VA, Lira PI. Dental trauma and associated factors in Brazilian preschoolers. Dent Traumatol. 2006 Dec;22(6):318-22.

10. Beltrão EM, Cavalcanti AL, Albuquerque SS, Duarte RC. Prevalence of dental trauma children aged 1-3 years in João Pessoa (Brazil). Eur Arch Paediatr Dent. 2007 Sep;8(3):141-3.

11. Robson F, Ramos-Jorge ML, Bendo CB, Vale MP, Paiva SM, Pordeus IA. Prevalence and determining factors of traumatic injuries to primary teeth in preschool children. Dent Traumatol. 2009 Feb;25(1):118-22.

12. Wendt FP, Torriani DD, Assunção MC, Romano AR, Bonow ML, Costa CT, et al. Traumatic dental injuries in primary dentition: epidemiological study among preschool children in South Brazil. Dent Traumatol. 2010 Apr;26(2):168-73.

13. Amorim LF, Estrela C, Costa LR. Retrospective study of traumatic dental injuries in primary teeth in a Brazilian specialized pediatric practice. Dent Traumatol. 2011 Oct;27(5):368-73.

14. Bonini GC, Bönecker M, Braga MM, Mendes FM. Combined effect of anterior malocclusion and inadequate lip coverage on dental trauma in primary teeth. Dent Traumatol. 2012 Dec;28(6):437-40.

15. Feldens CA, Kramer PF, Ferreira SH, Spiguel MH, Marquezan M. Exploring factors associated with traumatic dental injuries in preschool children: a Poisson regression analysis. Dent Traumatol. 2010 Apr;26(2):143-8.

16. Goettems ML, Ardenghi TM, Romano AR, Demarco FF, Torriani DD. Influence of maternal dental anxiety on oral health-related quality of life of preschool children. Qual Life Res. 2011 Aug;20(6):951-9.

17. Jorge KO, Moysés SJ, Ferreira EF, Ramos-Jorge ML, Zarzar PMA. Prevalence and factors associated to dental trauma in infants 1-3 years of age. Dent Traumatol. 2009 Apr;25(2):185-9.

18. Ferreira JM, Andrade EMF, Katz CR, Rosenblatt A. Prevalence of dental trauma in deciduous teeth of Brazilian children. Dent Traumatol. 2009 Apr;25(2):219-23.

19. Díaz JA, Bustos L, Brandt AC, Fernández BE. Dental injuries among children and adolescentes aged 1-15 years attending to public hospital in Temuco, Chile. Dent Traumatol. 2010 Jun;26(3):254-61.

20. Piovesan C, Guedes RS, Casagrande L, Ardenghi TM. Socioeconomic and clinical factors associated with traumatic dental injuries in Brazilian preschool children. Braz Oral Res. 2012 Sep-Oct;26(5):464-70.

21. Gordis L. Epidemiology. 4th ed. Philadelphia: Saunders Elsevier; 2009.

22. Corrêa-Faria P, Paiva SM, Pordeus IA, Ramos-Jorge ML. Influence and socioeconomic indicators on dental trauma in preschool children. Braz Oral Res. 2015;29(1):1-7. Epub 2014 Dec 9. doi: 10.1590/1807-3107BOR-2015.vol29.0015.

23. Feliciano KM, Caldas Jr AF. A systematic review of the diagnostic classifications of traumatic dental injuries. Dent Traumatol. 2006 Apr;22(2):71-6.

24. Burden DJ. An investigation of the association between overjet size, lip coverage, and traumatic injury to maxillary incisors. Eur J Orthod. 1995 Dec;17(6):513-7.

25. Bauss O, Freitag S, Röhling J, Rahman A. Influence of overjet and lip coverage on the prevalence and severity of incisor trauma. J Orofac Orthop. 2008 Nov;69(6):402-10.

26. Coutinho TC, Cajazeira MR. Retrospective study on the occurrence of primary incisor trauma in preschool children of a low-income area in Brazil. Eur J Paediatr Dent. 2011 Sep;12(3):159-62.

27. Tümen EC, Adigüzel O, Kaya S, Uysal E, Yavuz I, Ozdemir E, el tal. Incisor trauma in a Turkish preschool population: prevalence and socio-economic risk factors. Community Dent Health. 2011 Dec;28(4):308-12

28. Bonini GAVC, Marcenes W, Oliveira LB, Sheiham A, Bönecker M. Trends in the prevalence of traumatic dental injuries in Brazilian preschool children. Dent Traumatol. 2009 Dec;25(6):594-8.

29. Traebert J, Almeida IC, Marcenes W. Etiology of traumatic dental injuries in 11 to 13 -year-old schoolchildren. Oral Health Prev Dent. 2003 Sep;1(4):317-23. 